\title{
Effect of Plasma-Activated Water on Soaking, Germination, and Vigor of Erythrina velutina Seeds
}

\author{
Clodomiro Alves Jr., ${ }^{a, *}$ F.L.G. de Menezes, ${ }^{b}$ J. de O. Vitoriano, ${ }^{b} \&$ \\ D.L.S. da Silva ${ }^{\mathrm{C}}$ \\ aDepartment of Exact and Natural Sciences, Federal Rural University of Semiarid Mossoró, \\ 59.625-900 Brazil; ' bederal Rural University of Semiarid Mossoró-RN, Brazil; ' Center for \\ Agricultural Sciences State University of Piauí Teresina-Pi, Brazil \\ *Address all correspondence to: Clodomiro Alves Jr., Department of Exact and Natural Sciences, Federal Rural University \\ of Semiarid Mossoró, 59.625-900, Brazil, E-mail: clodomiro.jr@ufersa.edu.br
}

\begin{abstract}
In this study, physiology, germination, and seedling growth of seeds were analyzed after immersion in plasma-activated water. A dielectric barrier discharge (DBD) plasma dripper was developed to treat the water. Erythrina velutina seeds were immersed in water plasma-activated at a peak-to-peak voltage of 37,43 , or $49 \mathrm{kV}$ and monitored during imbibition. While the seeds were imbibing, $\mathrm{pH}$, electrical conductivity, and UV-Vis absorption of the exudate were measured. The seeds released substances during imbibition, maintaining $\mathrm{pH}$ between 5 and 6 . This fact may be used as a strategy to control plant physiology and seed germination. It was observed that water treated at a voltage of $49 \mathrm{kV}$ presented higher germination rates and seed vigor. Physiological aspects that explain this effect and its consequences on germinative response are discussed.
\end{abstract}

KEY WORDS: PAW, exudate, soaking, germination, scarification, dormancy

\section{INTRODUCTION}

Recent research has demonstrated the utility of plasma in agriculture, which is mainly related to the inactivation of pathogenesis, germination, and plant growth. ${ }^{1-5}$ Some researchers have successfully used plasma-activated water for irrigating seeds and plants and have obtained improvement in growth and germination..$^{6-9}$ This is possible because plasma leads to several changes when it is applied on the surface of water. One of these changes is modification of the chemical and electrical composition of the water due to the insertion of active species such as ions, electrons, and excited particles. ${ }^{10}$ This activity increases the acidity of the water and produces compounds such as $\mathrm{H}_{2} \mathrm{O}_{2}, \mathrm{NO}_{2}^{-}$, and $\mathrm{NO}_{3}{ }^{-11} \mathrm{~A}$ rapid analysis of the physiological and germinative response of seeds can be performed using the soaking assay. In this test, $\mathrm{pH}$ and electrical conductivity (EC) values and the substances leached from the soaking solution are monitored, as is the weight gain of the seeds. ${ }^{12}$ By monitoring $\mathrm{pH}$ and $\mathrm{EC}$, the relative concentrations of $\mathrm{H}^{+} / \mathrm{OH}^{-}$can be compared to estimate the ionic composition leached. ${ }^{13,14}$

All the studies reviewed so far show that the behavior of the solution $\mathrm{pH}$ and EC during imbibition is correlated with seed vigor. ${ }^{15}$ Our question is now inverted: Will seeds imersed in solutions with different $\mathrm{pH}$ values have different physiological and germinative responses? In the present work, plasma-activated water (PAW) was used to 
soak seeds. Seeds of Erythrina velutina Willd were chosen because they exhibit drought resistance, hardiness, and rapid growth, and can be used in recovering degraded soils. ${ }^{4}$

\section{MATERIALS AND METHODS}

\section{A. Plasma-Activated Water Production Source}

A schematic of the apparatus used to produce dielectric barrier discharge (DBD) plasmaactivated water is shown in Fig. 1. A hospital saline kit with a stainless-steel needle (diameter $0.8 \mathrm{~mm}$ ) was used as the water dripper. The cathode (needle) and anode (copper ring) were dielectrically separated by the walls of a glass tube (external diameter 12.0 $\mathrm{mm}$ and thickness $0.6 \mathrm{~mm}$ ). Distilled water dispensed from the dripper at a rate of 4 drops/s was exposed to DBD plasma using a voltage pulse sequence of $37 \mathrm{kV}, 43 \mathrm{kV}$, or $49 \mathrm{kV}\left(\mathrm{V}_{\text {peak-to-peak }}\right)$, repeated at a frequency of $15.5 \mathrm{kHz}$.

The droplets were collected in a 100-mL beaker, measured for $\mathrm{pH}$, and then stored for use in the soaking assay (Table 1). For plasma-activated distilled water, the $\mathrm{pH}$ value is directly associated mainly with nitrate and nitrite concentration. ${ }^{7}$

\section{B. Soaking Test}

For each experimental condition, 100 seeds were distributed across 4 beakers, each containing 25 seeds. The beakers were placed in a biological oxygen demand (BOD) germination chamber that was regulated with a photoperiod of $12 \mathrm{~h}$ at $25^{\circ} \mathrm{C}$. Imbibition was determined using an analytical balance at predetermined time intervals until protrusion of the radicle from the seed, at which point the seed was considered to have germinated.
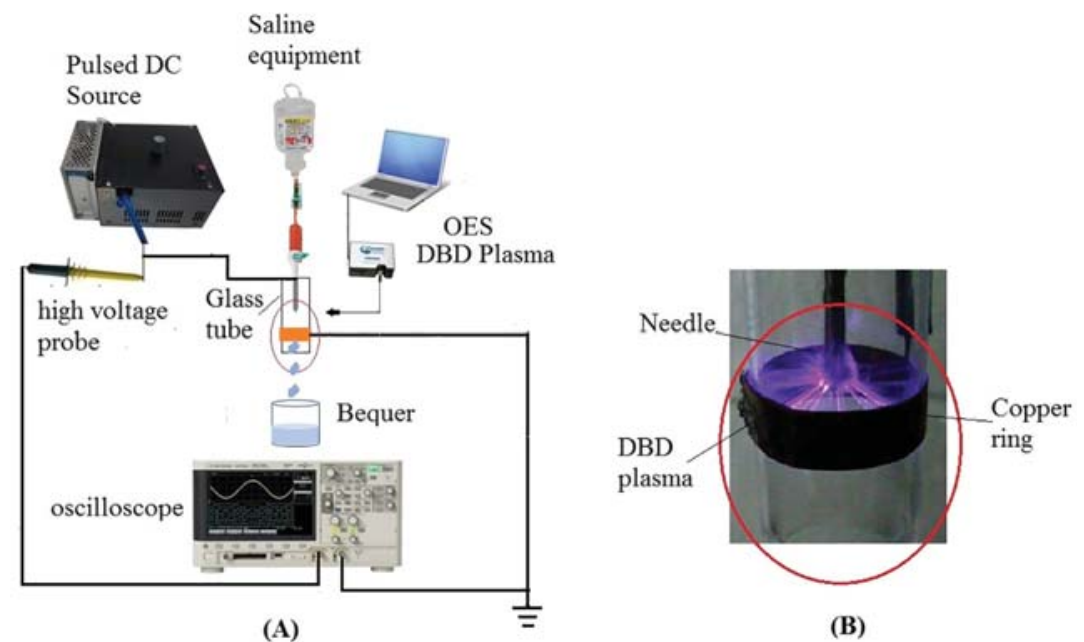

(B)

FIG. 1: Experimental apparatus used for plasma treatment of imbibition water. (A) schematic; (B) dripper during treatment. 
TABLE 1: Experimental conditions

\begin{tabular}{|l|c|c|c|c|}
\hline \multicolumn{1}{|c|}{ Condition } & $\mathbf{p H}$ & Flux (drops/s) & Frequency (kHz) & Voltage (kV) \\
\hline Untreated & 6.39 & 4 & 0 & 0 \\
\hline PAW 49 & 4.02 & 4 & 15.5 & 49 \\
\hline PAW 43 & 5.13 & 4 & 15.5 & 43 \\
\hline PAW 37 & 5.82 & 4 & 15.5 & 37 \\
\hline
\end{tabular}

Before each measurement, the seeds were placed on sterile paper to remove excess water. The relative percentage of imbibition (I) was defined according to Eq. (1), where $m_{0}$ is the initial total seed mass and $m_{t}$ is the total seed mass for each measurement time. The experimental design was completely randomized.

$$
I(\%)=\left[\frac{\left(m_{t}-m_{0}\right)}{m_{0}}\right] \times 100
$$

During the seed weighing, aliquots of the soaking solution were removed for EC and $\mathrm{pH}$ measurement. The EC measurements were performed using an Oakton PC 450 conductivity meter, and $\mathrm{pH}$ measurements were performed using a TEC-3MP $\mathrm{pH}$ meter. Additionally, aliquots of the soaking solution were extracted to analyze the substances leached by the seeds using UV-Vis absorption spectroscopy. It was found that after radicle protrusion, EC and $\mathrm{pH}$ values were strongly altered by the presence of leached substances.

\section{Germination and Seed Vigor Tests}

For the germination tests, seeds soaked in distilled water and seeds soaked in activatedplasma water (PAW 49, PAW 43, and PAW 37) were used. For each condition, 100 seeds divided into four replicates of 25 were used. The germination tests were carried out in gerbox boxes in a BOD germination chamber at $25^{\circ} \mathrm{C}$ and a photoperiod of $12 \mathrm{~h}$. The seeds were placed between layers of germitest paper moistened with an amount of water equal to 2.5 times the mass of the paper. The number of seedlings that emerged were counted from the 1 st to the 23 rd day. The experiment was completely randomized. The percentage of cumulative germination $(G)$, calculated for each day, was plotted as a function of time in days [Eq. (2)], where $N_{f}$ is the cumulative number of seeds germinated in each day and $N_{i}$ is the number of sown seeds.

$$
G(\%)=\frac{N_{f}}{N_{i}} \times 100
$$

The experimental points were adjusted according to the Richards model, which models population growth by transforming functional parameters into populations. The

Volume 9, Issue 2, 2019 
parameters obtained were as follows: $V i$ (viability), percentage of final germination, indicating the viability of germination of a seed lot; $M e$ (median), which provides the time at which $50 \%$ of the germination of a seed lot occurs and characterizes the rate of that process; $Q u$ (dispersion), which describes the time deviation interval of the Richards curve in relation to $\mathrm{Me}$ and indicates the dispersion of germination times in a seed lot; and $S k$ (asymmetry), which represents the asymmetry of the Richards curve relative to the inflection point and indicates asymmetry in the frequency distribution of germination times. ${ }^{16,17}$

For vigor analysis, the root, stem, and shoot lengths were measured only for the untreated and PAW 49 conditions. The PAW 49 condition was chosen because it was the one with the highest germinative response. For each condition, 25 seeds were used. The test was carried out in gerbox boxes at $25^{\circ} \mathrm{C}$ in a germination chamber with a photoperiod of $12 \mathrm{~h}$. The seeds were placed between layers of germitest paper moistened with an amount of water equal to 2.5 times the mass of the paper used. After 23 days, the seedlings were extracted and their root, stem, and shoot lengths were determined. The experimental design was completely randomized.

All data are presented as mean value \pm standard error (SE) of three replicates. Analyses were performed using SPSS v. $16.0,{ }^{18}$ and the variance $(P<0.05)$ of the data was analyzed by ANOVA for comparing untreated and plasma-treated groups (Duncan's test).

\section{RESULTS AND DISCUSSION}

\section{A. Endocarp Structure, Composition, and Water Path from the Endocarp Surface to the Seed}

The $\mathrm{pH}$ of the solution was monitored during the first 5 days of imbibition (Fig. 2). The exudate appeared to function as a buffering of the solution, maintaining $\mathrm{pH}$ in the range of 5.0 to 5.5 .

During imbibition, seeds generally exude metabolites such as sugars, organic acids, and $\mathrm{H}^{+}$ions, which acidify the medium and cause a decrease in $\mathrm{pH}$ of the exudate. ${ }^{12} \mathrm{In}$ the present work, this behavior was verified only for seeds that were imbibed in water with a $\mathrm{pH}$ higher than 5.5. For water with a lower $\mathrm{pH}$, there was an increase in $\mathrm{pH}$ of the exudate. This suggests that the ionic interactions of the electrogenerated compounds and leached seeds have a buffering action even before emission of the radicle. Such behavior is characteristic of biological systems in which cells regulate $\mathrm{pH}$ with the aid of weakly conjugated acid-base pairs. ${ }^{19}$ In the present case, $\mathrm{pH}$ is maintained between 5.0 and 5.5. From these results, it can be stated that the physiological response of a seed may be altered by the substances exuded from neighboring seeds. Soaking tests, when conducted with several seeds in the same container, should account for this fact. EC for all samples except PAW 49 had an initial value of approximately $15 \mu \mathrm{S} / \mathrm{cm}$ (Fig. 3), which abruptly increased before the first emission of radicles occurred at approximately $48 \mathrm{~h}$. For the PAW 49 sample, this initial value was approximately $70 \mu \mathrm{S} / \mathrm{cm}$, which was maintained approximately constant before the emission of the radicle, following the same tendency of the other conditions for greater imbibition times. Since $\mathrm{pH}$ oscillated 


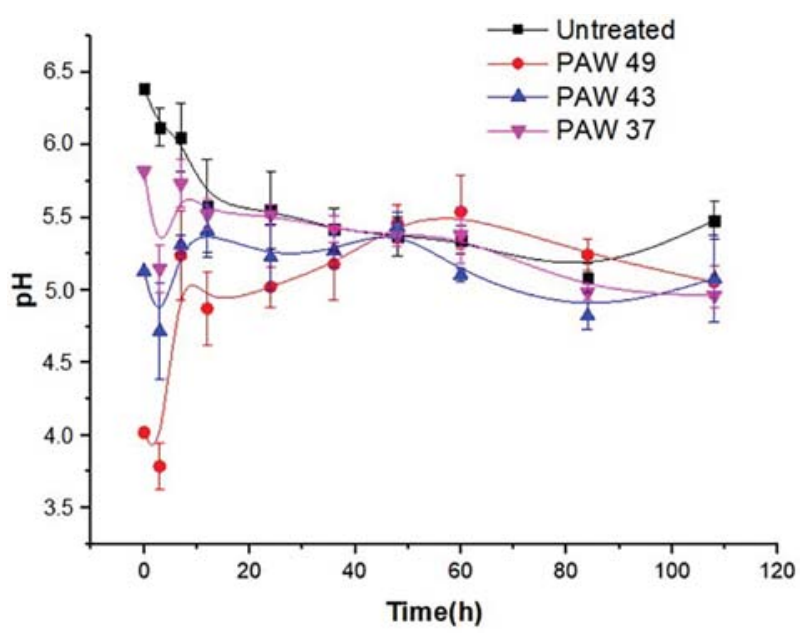

FIG. 2: Behavior of soaking solution $\mathrm{pH}$ during imbibition test, showing tendency for $\mathrm{pH}$ stability

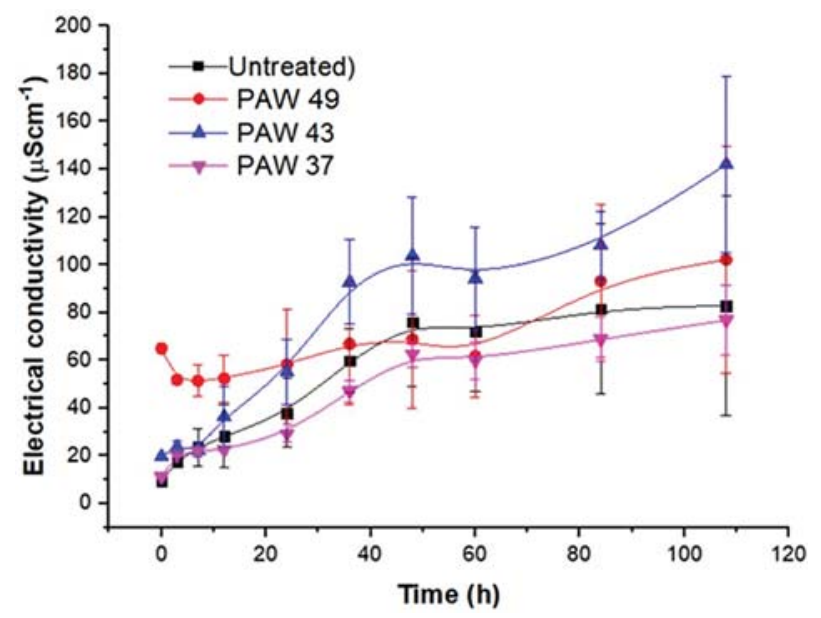

FIG. 3: Seed imbibition water conductivity until radicle protrusion

around a constant value while EC had an abrupt growth until radicle emission, except for PAW 49, it is believed that other ions contribute more to electric mobility than $\mathrm{H}^{+}$ and $\mathrm{OH}^{-}$.

The initial value of EC in the PAW 49 solution, compared to the other solutions, could be attributed to other ions in addition to the higher initial concentration of $\mathrm{H}^{+}$. This higher value suggests that shortly after immersion there is a release of ions other than the initial $\mathrm{H}^{+}$and $\mathrm{OH}^{-}$in the PAW 49 solution. Visually observing the solution during the first 6 days of imbibition, it was found that the untreated solution was yellowing whereas the PAW 49 solution tended to turn brown. When these solutions were analyzed in the 
UV-Vis absorption spectrophotometer after radicle emission, two well-defined peaks were observed (Fig. 4A). A more intense peak occurred at $\lambda=230 \mathrm{~nm}$ for the untreated solution, and a slightly shifted peak $(\lambda=240 \mathrm{~nm})$ occurred for the plasma-treated solution. The other peak, which was equivalent for the two solutions, occurred at $\lambda=280 \mathrm{~nm}$. Observing the absorption spectrum at different soaking times (Fig. 4B), it was found that the two peaks increased in intensity but that there was no shift in wavelength. It was also noted that the difference in intensity between the peaks of the PAW 49 sample and the untreated sample increased with imbibition time. This spectrum indicates the oxidation of lignin-related phenolic compounds. ${ }^{20}$

In the PAW 49 solution, the lignin absorption peaks were more intense than in the control solution. This suggests a higher exudation of lignocellulosic compounds from the tegument of Erythrina velutina seed in aqueous acid medium (plasma-treated water), in which the reactions of oxygenated groups predominate. Additionally, there were more chemical interactions between chromophoric groups of the lignin, due to the presence of electrogenerated species in the water treated with plasma (PAW 49), and free phenolic groups, which contributed to the light-induced yellowing. ${ }^{21}$ Because lignin (L) behaves as a colloidal solution ${ }^{22}$ and tends to be precipitated at lower $\mathrm{pH}$, the availability of $\mathrm{H}^{+}$ions promotes the protonation of phenolic groups and decreases the repulsion forces between molecules, leading to increased coagulation and precipitation. We can therefore infer that the reduction in $\mathrm{pH}$ caused by the activation of water by plasma increases the removal of lignin from the seed. This higher extraction, in turn, affects seed imbibition because physical dormancy is generally associated with the impermeability of the seed tegument through hydrophobic substances such as lignin. ${ }^{23}$

The peak at $280 \mathrm{~nm}$, which was more intense in the PAW 49 solution than in the control solution, may be associated with catalase. This enzyme is an antioxidant that the
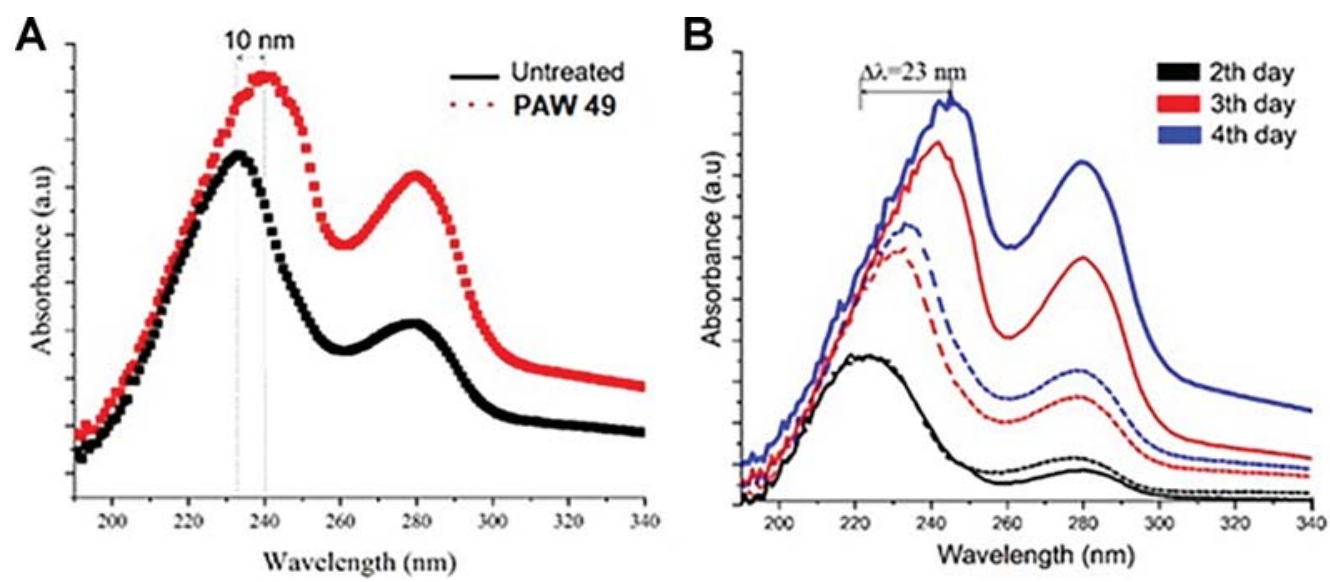

FIG. 4: (A) UV-Vis absorbance spectrum of exudate; (A) after radicle protrusion; (B) leaching of seeds soaked in untreated water (dotted lines) and PAW 49 condition (solid line) 
seed releases to control the action of reactive oxygen species (e.g., $\mathrm{H}_{2} \mathrm{O}_{2}$ ) that are generated in plant cells during periods of environmental stress ${ }^{24}$ or, in our case, by the interaction between the exudate and the water in which the seed was immersed. This increase in catalase activity is especially important, as the activity of this enzyme is directly linked to the germination capacity, ${ }^{25}$ development, and tolerance of the plant ${ }^{26}$

The effects of such changes in enzymatic activity on the germinative behavior of the seeds was verified in the curves of the cumulative germination percentages obtained in this study (Fig. 5). It was observed that seeds soaked in untreated water presented delayed germination compared to the other seeds. Additionally, the germination behavior of the untreated seeds had a worse fit to the Richards curve. Considering the setting parameters between the Richards and sigmoidal curves (Fig. 1), the population parameters $V_{i}, M_{e}, Q_{u}$, and $S_{k}$ were obtained (Table 2). Viability $\left(V_{i}\right)$ had a statistically significant increase in plasma-activated conditions compared to the untreated conditions. Whereas

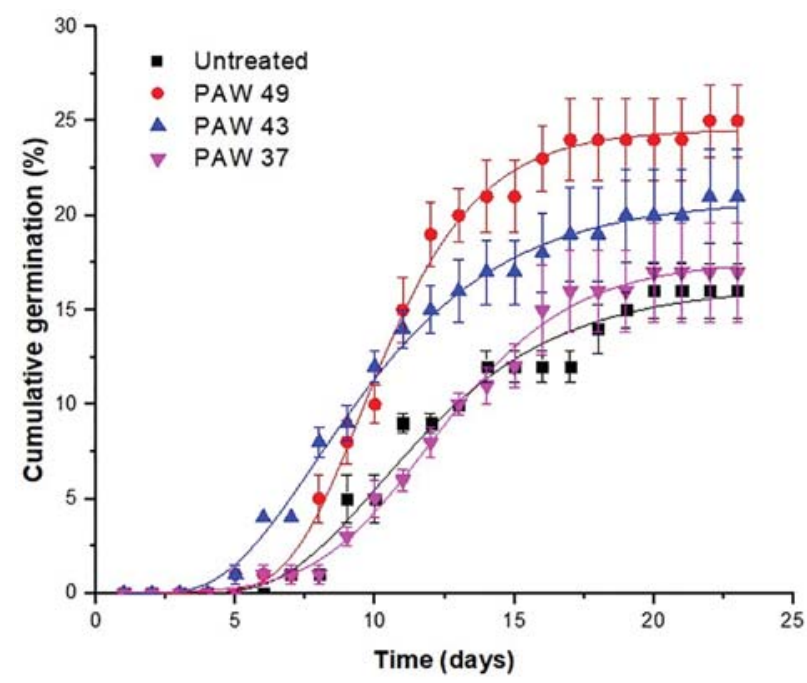

FIG. 5: Germination curves calculated using Richard fitting. All data points represent mean \pm standard deviation for 100 seeds $(25 \times 4$ replicates $)$.

TABLE 2: Population parameters $V_{i}$ (viability), $M_{e}$ (median germination), $Q_{u}$ (dispersion), and $S_{k}$ (skewness) of Richards equation for of E. velutina germination

\begin{tabular}{|l|c|c|c|c|}
\hline \multicolumn{1}{|c|}{ Parameter } & Untreated & PAW 49 & PAW 43 & PAW 37 \\
\hline$V_{i}(\%)$ & $16.24 \pm 0.87^{\mathrm{d}}$ & $24.53 \pm 0.34^{\mathrm{a}}$ & $20.85 \pm 0.45^{\mathrm{c}}$ & $17.59 \pm 0.40^{\mathrm{d}}$ \\
\hline$M_{e}$ (days) & $11.60 \pm 0.95^{\mathrm{a}}$ & $10.25 \pm 0.34^{\mathrm{a}}$ & $9.51 \pm 0.51^{\mathrm{a}}$ & $12.05 \pm 0.38^{\mathrm{a}}$ \\
\hline$Q_{u}($ days $)$ & $2.83 \pm 0.47^{\mathrm{a}}$ & $1.88 \pm 0.26^{\mathrm{b}}$ & $2.86 \pm 0.22^{\mathrm{a}}$ & $2.52 \pm 0.29^{\mathrm{a}}$ \\
\hline$S_{k}(\%)$ & $0.52 \pm 0.08^{\mathrm{a}}$ & $0.39 \pm 0.06^{\mathrm{b}}$ & $0.57 \pm 0.36^{\mathrm{a}}$ & $0.21 \pm 0.06^{\mathrm{c}}$ \\
\hline
\end{tabular}

a,b,c,d Statistical differences for the same parameter between treatments groups at the $5 \%$ level according to Turkey test.

Volume 9, Issue 2, 2019 
the untreated samples presented a 16.24\% germination rate, the PAW 49 and PAW 43 samples presented values of $24.53 \%$ and $20.85 \%$, respectively. Seeds treated at lower $\mathrm{pH}$ values systematically showed higher $V_{i}$ values. All seeds reached $50 \%$ germination $\left(M_{e}\right)$ at approximately 10.8 days. Although the PAW 49 and PAW 43 seeds reached 50\% germination in less time, these differences were not statistically significant. By observing the dispersion of the germination time $\left(Q_{u}\right)$, the superiority of the PAW 49 seeds, which presented the lowest value, was verified. That is, of all the seeds studied, the PAW 49 seeds presented the best germination results.

The seedling length test was performed in a manner analogous to the germinative test, but only under the untreated and PAW 49 conditions. PAW 49 was chosen because it was the one with the highest germinative response. The average lengths of the roots, stems, and shoots (length of stem to last leaf) were considered (Fig. 6). Although not statistically significant, all mean values for the PAW 49 seeds were higher than those for the untreated seeds.

\section{CONCLUSION}

Erythrina velutina seeds were imbibed in water activated by plasma DBD whose $\mathrm{pH}$ was controlled by the applied discharge voltage. From the obtained results, we can draw the following conclusions:

- Ionic interactions between the electrogenerated compounds and the compounds leached by the seeds during imbibition resulted in a balance by buffering action, even before emission of the radicle.

- The buffering action in the seeds maintained a soaking solution $\mathrm{pH}$ between 5.0 and 5.5.

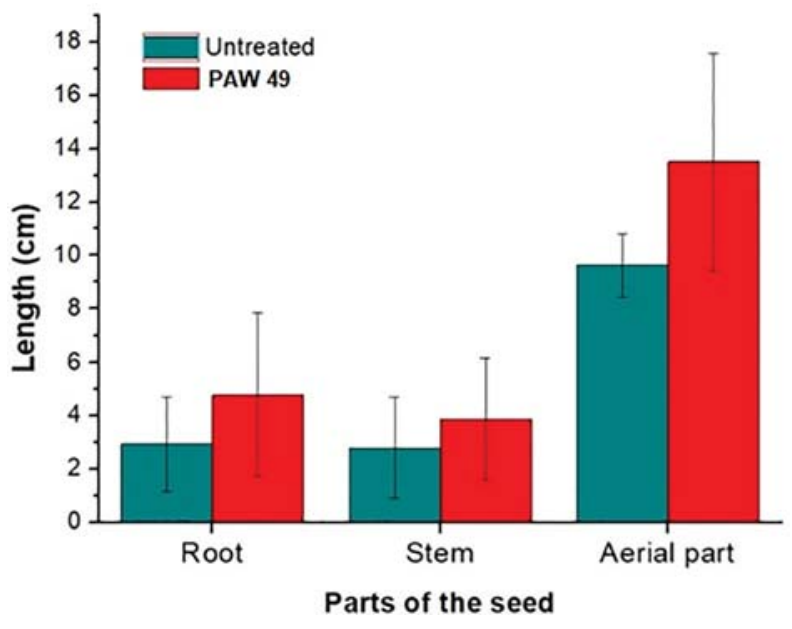

FIG. 6: Lengths of roots, stems, and aerial parts of plants originated from seeds soaked in activated-plasma and untreated water 
- The exuded solutions had UV-Vis absorption peaks at 230 and $280 \mathrm{~nm}$. In the solutions with plasma-treated water, the peaks were more intense and were displaced from 230 to $240 \mathrm{~nm}$.

- Seeds imbibed with plasma-treated water had a higher rate of germination and vigor than those imbibed in untreated water, in the reverse order of $\mathrm{pH}$ value.

- The best germination and vigor were observed in seeds soaked in plasma-treated water with $\mathrm{pH}$ equal to 4 .

\section{ACKNOWLEDGMENTS}

This project was funded by the National Council for Scientific and Technological Development (CNPQ-430863/2016-0) and the National Institute of Surface Engineering (CNPq-465423/2014-0).

\section{REFERENCES}

1. Tong J, He R, Zhang X, Zhan R, Chen W, Yang S. Effects of atmospheric pressure air plasma pretreatment on the seed germination and early growth of Andrographis paniculata. Plasma Sci Technol. 2014;16(3):260-6.

2. Ling L, Jiafeng J, Jiangang L, Minchong S, Xin H, Hanliang S, Yuanhua D. Effects of cold plasma treatment on seed germination and seedling growth of soybean. Sci Rep. 2014;4:5859.

3. Bormashenko E, Shapira Y, Grynyov R, Whyman G, Bormashenko Y, Drori E. Interaction of cold radiofrequency plasma with seeds of beans (Phaseolus vulgaris). J Exp Bot. 2015;66(13):4013-21.

4. Alves Jr C, Vitoriano JO, Silva DLS, Farias ML, Dantas NBL. Water uptake mechanism and germination of Erythrina velutina seeds treated with atmospheric plasma. Sci Rep. 2016;3:3722.

5. Poiata A, Motrescu IA, Nastuta DE, Creanga GP. Microorganism response to atmospheric pressure helium plasma DBD treatment. J Electrostat. 2010;68:128-31.

6. Naumova IK, Maksimov AI, Khlyustova AV. Stimulation of the germinability of seeds and germ growth under treatment with plasma-activated water. Surf Eng Appl Elect. 2011;47(3):263-5.

7. Park DP, Davis K, Gilani S, Alonzo C-A, Dobrynin D, Friedman G, Fridman A, Rabinovich A, Fridman G. Reactive nitrogen species produced in water by non-equilibrium plasma increase plant growth rate and nutritional yield. Curr Appl Phys. 2013;13:S19-29.

8. Sivachandiranab L, Khacef A. Enhanced seed germination and plant growth by atmospheric pressure cold air plasma: combined effect of seed and water treatment. RSC Adv. 2017;7:1822-32.

9. Takano K, Takahata J, Takaki K, Satta N. Improvement of growth rate of Brassica para var. perviridis by discharge inside bubble underwater in hydroponic cultivation. Electr Commun Jpn. 2016;99(11):467-72.

10. Bruggeman P, Leys C. Non-thermal plasmas in and in contact with liquids. J Phys D Appl Phys. 2009;42(5):053001.

11. Kamgang-Youbi G, Herry JM, Meylheuc T, Brisset JL, Bellon-Fontaine MN, Naitali M. Microbial inactivation using plasma-activated water obtained by gliding electric discharges. Lett Appl Microbiol. 2009;48(1):13-18.

12. Weitbrecht K, Muller K, Leubner-Metzger G. First off the mark: early seed germination. J Exp Bot. 2011;62(10):3289-309.

13. Krämer M, Schüle M, Schütz L. A method to determine rainwater solutes from $\mathrm{pH}$ and conductivity measurements. Atmos Environ. 1996;30(19):3291-300.

Volume 9, Issue 2, 2019 
14. Shen J, Tian Y, Li Y, Ma R, Zhang Q. Bactericidal effects against S. aureus and physicochemical properties of plasma activated water stored at different temperatures. Sci Rep. 2016;6:28505.

15. Matthews S, Powell A. Electrical conductivity vigour test: physiological basis and use. STI. 2006;131:132-5.

16. Šerá B, Sery M, Stranak V, Spatenka P. Does cold plasma affect breaking dormancy and seed germination? A study on seeds of Lamb's Quarters (Chenopodium álbum agg.). Plasma Sci Technol. 2009;11(6):750-4.

17. Richards FJ. A flexible growth function for empirical use. J Exp Bot. 1959;(10):290-300.

18. Hall L. A guide to doing statistics in second language research using SPSS and R. 2nd ed. New York: Taylor and Francis Group; 2015.

19. Salis A, Monduzzi M. Not only pH. Specific buffer effects in biological systems. Curr Opin Colloid Interface Sci. 2016;23:1-9.

20. Pardo I, Chanagá X, Vicente AI, Alcalde M, Camarero S. New colorimetric screening assays for the directed evolution of fungal laccases to improve the conversion of plant biomass. BMC Biotech. 2013;13(90):1-14.

21. Magnus P, Parkås J. Review: light-induced yellowing of lignocellulosic pulps-mechanisms and preventive methods. BioResources. 2012;7(4):5995-6040.

22. Lindströmn T. The colloidal behavior of kraft lignin. Colloid Polym Sci. 1979;258(2):168-73.

23. Majd R, Aghaiel P, Monfared EK, Alebrahim MT. Evaluating some treatments on breaking seed dormancy in Mesquite. Int J Agron Plant Prod. 2013;4(7):1433-9.

24. Chauhan DS, Deswal DP, Dahiya OS, Punia RC. Change in storage enzyme activities in natural and accelerated aged seed of wheat (Triticum aestivum). Indian J Agric Sci. 2011;81(11):1037-40.

25. Prodanović O, Prodanović R, Bogdanović J, Mitrović A, Milosavić N, Radotić K. Antioxidative enzymes during germination of two lines of Serbian spruce [Picea omorika (Panč.) Purkyně]. Arch Biol Sci. 2007;5(3):209-16.

26. Cai F, Mei L, An X, Gao S, Tang L, Chen F. Lipid peroxidation and antioxidant responses during seed germination of Jatropha curcas. Int J Agric Biol. 2011;13(1):25-30. 